\title{
Peer development as an alternative to peer observation: a tool to enhance professional development
}

\author{
Jenny Byrne*, Hazel Brown, and Doreen Challen \\ School of Education, University of Southampton, Southampton, UK
}

Building 34, School of Education, University of Southampton, Highfield, Southampton, SO17 $1 \mathrm{BJ}, \mathrm{UK}$

\section{(Received; final version received)}

Keywords: peer observation, professional development, collaborative learning

\begin{abstract}
Many Higher Education institutions worldwide require that all academic staff undergo a peer observation of teaching each academic year. Within one department in a university in the South of England, questions have arisen about the value and purpose of the traditional 'peer observation' process, and as a result a new voluntary system of 'peer development' has been introduced. This paper explains the rationale underpinning the new peer development process, and explores its worth and value to those who have participated in it as a mechanism for professional development. Reflections on the process are considered, along with what can be done to improve the new system.
\end{abstract}

\section{Introduction and Background}

Peer observation of teaching has become an increasingly common practice in higher education institutions worldwide, partly as a result of pressures from internal and external quality assurance systems that require institutions to examine the effectiveness of their educational provision (Berthiaume, 2006; Hendry and Dean, 2002; McMahon, Barrett and O'Neill, 2007; Shortland, 2004). From this perspective, the purpose of peer observation may be thought of as accounting for, and improving, the quality of teaching with the aim of improving student learning (Bennett and Barp, 2008; Hammersley-Fletcher and Orsmond, 2004; Shortland, 2004). However, many peer observation processes are developed by management and have a 'top-down' approach that may encourage compliance rather than engagement (HammersleyFletcher and Orsmond, 2005; Shortland, 2004). Primarily evaluative (Peel, 2005), these practices offer little benefit to observed members of staff with regard to their own professional development. In this respect, peer observation of teaching can be seen to contribute to the growing catalogue of procedures that are part of the increasing audit culture in Higher Education (Darbyshire, 2007; Hendry and Dean, 2002; Shore, 2008). As such, peer observation of teaching may have become a tool to measure teaching performance (or underperformance) and be used in the appraisal of individuals. Such a tool then adds to the repertoire of those in authority where individuals may be subjected to the hegemony of a 'disciplinary society' and its normalising judgements (Foucault, 1979). In these instances, where power and social relations are imbalanced, the opportunity for peer observation of teaching to provide the basis for professional development is lost (Gosling, 2002).

Since becoming part of the landscape of academic life, peer observation of teaching has been dealt with quite unimaginatively. It has been interpreted, almost exclusively, to mean the observation of one person by another, sometimes with an agreed focus, performing a 
standard teaching session such as a lecture or seminar in a conventional 'classroom' setting (Gosling and O'Connor, 2006; Kell, 2005; Marshall, 2004). However teaching occurs in a range of settings, and if peer observation is to be used to support improvement of teaching, then a one-off observation of a lecture is not sufficient to enable this to happen. We must therefore consider encompassing all forms of teaching, including courses taught online, as opportunities to enhance professional expertise by engaging in peer development (Bennet and Barp, 2008).

Furthermore, a one-off peer observation in itself does not necessarily lead to improvement in teaching. Active engagement in pedagogical theory and discourse, critical reflection and collaboration with colleagues are all necessary for developing an understanding of what constitutes good teaching at an individual level, and for real improvement to occur (Hammersley-Fletcher and Orsmond, 2004; Hendry and Dean, 2002; Peel, 2005). This type of in-depth engagement with colleagues requires time and commitment that may be difficult to manage but the benefits of such collaborations are manifold. As Luchoomun (2007) notes, empowering teachers to collaborate over sustained periods of time leads to highly positive outcomes such as professional interactions, leadership and improved attitudes, as well as improving the quality of teaching. Such an approach implies that colleagues will engage in specific enterprises and learn together over time. This involves not only sharing knowledge but, more importantly, developing processes of learning together by being active participants in a cohesive group which can be thought of as a professional learning community (FeimanNemser, 2001). If such learning communities are to be successful, a non-judgemental ethos whereby colleagues have equal status, can share ideas and develop their thinking in an atmosphere of trust and cooperation, rather than feeling threatened or undermined, is essential (Schuck, Aubusson and Buchanan, 2008). Mutual respect and responsibility are therefore important foundations for long-term improvements to practice. In addition, Aubusson et al. (2007) comment that mutual responsibility for the learning of others is essential in developing practices that reflect the enterprises and the social reality of the group.

Attendant upon such mutual responsibility for sustained and successful professional learning is the commitment of the group of peers to their learning. This requires a willingness to give time and actively participate in the group process. For the success of such groups, professional dialogue in the form of learning conversations is considered essential (FeimanNemser, 2001; Hammersley-Fletcher and Orsmond, 2004). Conversations are highly valuable in the learning process because they enable reflection and engage participants in dialogue which "involves participants in exploration and critique of the reasons and assumptions associated with their positions" (Haigh, 2005: 8). Learning conversations are therefore characterised by a focus on the learner(s) and are vehicles to facilitate critical reflection through dialogue (Allard et al., 2007; Bell, 2001). Critical reflection enhanced by dialogue with colleagues is at the heart of peer mentoring and coaching (Feiman-Nemser, 2001; Le Cornu, 2005; Little, 2005; Zwart et al., 2007) whilst the notion of the reflective practitioner (Schön, 1983) has been long recognised as a model to improve practice. Reflections can take place with others or individually. Self-reflection as part of self-study enhances not only the individual's learning but can be a crucial element advancing the learning of the group. Wilcox (2009) proposes that self study transfers personal reflections to a public domain through a process of reflexivity that enables 'critical discourse' between group members. Self study can therefore provide a transformative learning process in which individuals or groups act differently and a new perspective is shared in the learning community.

In the context of the peer development project discussed here, a double benefit can therefore be discerned. Firstly, there is the opportunity for individual reflection on one's own practice, and secondly, perhaps more importantly, the chance to share reflections with colleagues through dialogue. These various aspects of practice are considered to be effective 
mechanisms for professional development (Zwart et al., 2007) and are integral to the peer development process discussed in this paper.

What follows is a case study of one department within a (pre-1992) university in the South of England. It describes the changes that took place as a result of discontent with conventional peer observation of teaching. The research consisted of two phases, phase 1 to ascertain views of academic staff about the existing peer observation process, and phase 2 to evaluate the alternative system that was devised in the light of phase 1 findings.

\section{Methodology}

The introduction of the peer development process, the evaluation of its impact on colleagues taking part and subsequent reflection on how the new model could be improved sits within the action research paradigm (Carr and Kemmis, 1986). Specific research questions provided a focus for data collection:

- What were participants' views of the existing system of peer observation of teaching?

- Why did participants choose to engage with the new peer development process?

- What did participants gain from engagement with the peer development process?

- What issues arose for participants and for the institution?

In both phases, an initial questionnaire was followed up by semi-structured, one-to-one interviews with volunteers. Both questionnaire and interview data were coded using a broadly grounded approach (Babbie 2009; Strauss and Corbin 1998) which enabled responses to be categorised for purposes of comparison. Categories that emerged from each set of data informed analysis of the other (see findings). Ethical approval was obtained prior to the research taking place.

In phase 1, 36 out of 67 full-time and part-time eligible staff (54\%) volunteered to complete an initial questionnaire, having been approached by personalised letter, with the questionnaire included in the mailing; staff could request an electronic version if preferred. Open-ended questions were used to ascertain respondents' views on the purpose and advantages of the existing system of peer observation, and whether they perceived a need for change. Of the 36 respondents, 10 volunteered for a follow-up interview.

Twenty-six (39\%) staff opted to take part in the peer development process. In phase 2, a second questionnaire was sent to all 26 participants, of which 18 (70\%) were returned; some participants completed the questionnaire on behalf of their peer group. Five of the respondents, mainly representing initial teacher training programmes, volunteered for subsequent interviews. This was a convenience sample, and would have been strengthened by the inclusion of more representatives of other programmes.

\section{The peer development process}

Alterations to the system of peer observation were intended to facilitate and enhance the professional developmental of teaching staff through a collaborative process. At the heart of the peer development process is the opportunity to develop one's own practice in a meaningful way by engaging in dialogue with others about pedagogy. As such, the emphasis on collaboration and mutual professional development is strengthened, and may help to enhance long-term professional development and develop communities of practice.

Gosling (2002) offers three models of peer observation of teaching that range in emphasis from a purely evaluative process to a process of mutual engagement in discussion about teaching (Table 1, columns a-c). The existing peer observation format within the 
institution appeared to be based on the 'peer review' (column c) in some respects, but as a one-off routine event, conducted for accountability purposes, was more akin to that of the 'evaluation' model (column a) in terms of purpose and outcomes. Additionally, no model or process is ideal, and Gosling (2002) warns that the 'peer review' model may lead to complacency and become unfocused. This was recognised as an issue within the peer observation process by academic staff, and was a key driver to implement change via the peer development process.

It is nonetheless the ethos of the 'peer review' model (column c) that forms the rationale and basis for the new 'peer development' (column d). This is designed to enable colleagues to identify an aspect of practice of mutual interest that they wish to develop, and explicitly expands the focus area to include aspects of professional practice other than those traditionally regarded as 'teaching', such as tutorial support, placement supervision, assessment and course design, while also removing the requirement for observation. Staff are expected to plan and organise their own peer development across the year, and engage in dialogue through meetings or alternative modes of communication on a number of occasions. As a result, ideas about learning and teaching can be incorporated into practice through a shared and reciprocal process that has potential for greater impact than via a one-off observation of teaching.

It is thought that a number of benefits might accrue from taking part in the peer development process. These relate to the provision of:

- a non-judgemental climate in which colleagues are willing to be frank and honest so that they can discuss issues about teaching and learning for their mutual professional development;

- planned, rather than ad hoc, conversations about the quality of teaching and learning, and so helping to develop dialogue about teaching and learning at a more scholarly level;

- longer-term benefits for participants, by facilitating joint development through confidential discussion;

- opportunities for a shared understanding of problematic issues and possible solutions, and offering the possibility to find ways for improvement and opportunities to evaluate them;

- a means to develop as a community of practice;

- opportunities for colleagues to research and develop pedagogy.

Table 1. Models of Peer Observation of Teaching (adapted from Gosling, 2002)

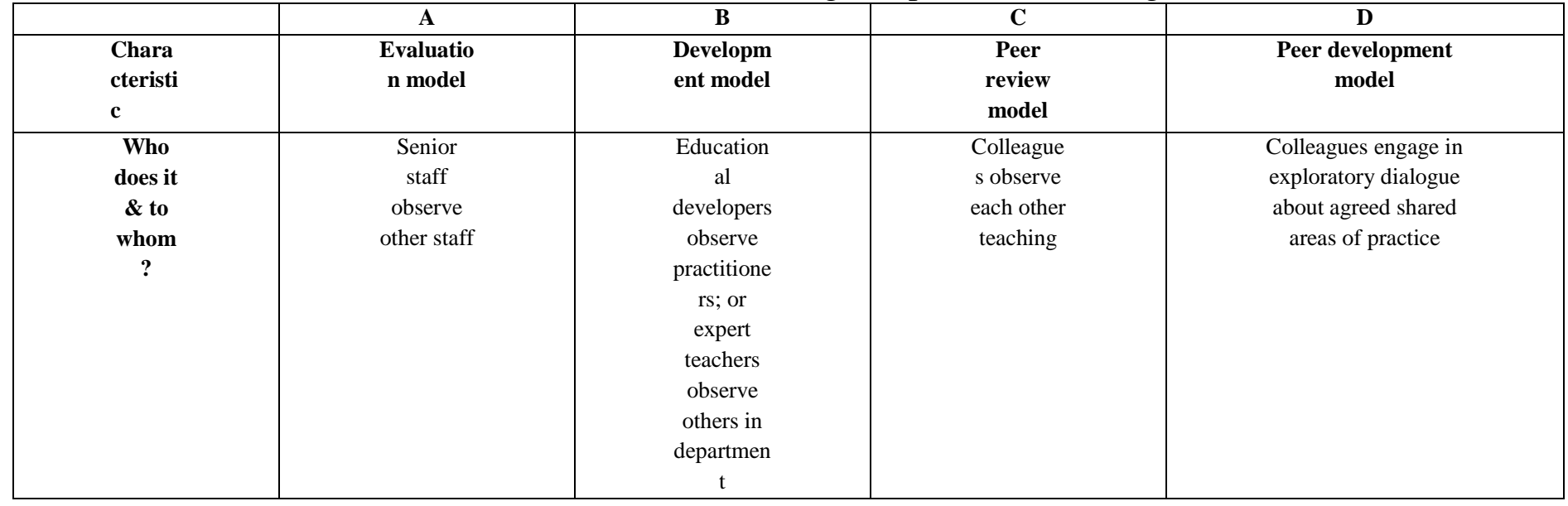




\begin{tabular}{|c|c|c|c|c|}
\hline $\begin{array}{c}\text { Purpos } \\
\text { e }\end{array}$ & $\begin{array}{c}\text { Identify } \\
\text { under- } \\
\text { performan } \\
\text { ce, } \\
\text { confirm } \\
\text { probation, } \\
\text { appraisal, } \\
\text { promotion } \\
\text {, quality } \\
\text { assurance, } \\
\text { assessmen } \\
\text { t }\end{array}$ & $\begin{array}{c}\text { Demonstra } \\
\text { te } \\
\text { competenc } \\
\text { y/improve } \\
\text { teaching } \\
\text { competenc } \\
\text { ies; } \\
\text { assessmen } \\
\mathrm{t}\end{array}$ & $\begin{array}{c}\text { Engageme } \\
\text { nt in } \\
\text { discussion } \\
\text { about } \\
\text { teaching; } \\
\text { self and } \\
\text { mutual } \\
\text { reflection }\end{array}$ & $\begin{array}{c}\text { Engagement in } \\
\text { discussion about } \\
\text { practice; self and } \\
\text { mutual reflection }\end{array}$ \\
\hline $\begin{array}{c}\text { Outco } \\
\text { me }\end{array}$ & $\begin{array}{c}\text { Report/jud } \\
\text { gement }\end{array}$ & $\begin{array}{c}\text { Report/act } \\
\text { ion plan; } \\
\text { pass/fail }\end{array}$ & $\begin{array}{l}\text { Analysis, } \\
\text { discussion } \\
\text {, wider } \\
\text { experience } \\
\text { of } \\
\text { teaching } \\
\text { methods }\end{array}$ & $\begin{array}{c}\text { Analysis, discussion, } \\
\text { wider experience of } \\
\text { practice, changes to } \\
\text { practice }\end{array}$ \\
\hline $\begin{array}{c}\text { Relatio } \\
\text { nship } \\
\text { of } \\
\text { observ } \\
\text { er to } \\
\text { observ } \\
\text { ed }\end{array}$ & Power & Expertise & $\begin{array}{l}\text { Equality/ } \\
\text { mutuality }\end{array}$ & $\begin{array}{l}\text { Equality/mutuality in } \\
\text { relation to the peer } \\
\text { development process }\end{array}$ \\
\hline $\begin{array}{c}\text { Confid } \\
\text { entialit } \\
y\end{array}$ & $\begin{array}{c}\text { Between } \\
\text { manager, } \\
\text { observer } \\
\text { and } \\
\text { observed }\end{array}$ & $\begin{array}{c}\text { Between } \\
\text { observer } \\
\text { and } \\
\text { observed, } \\
\text { examiner }\end{array}$ & $\begin{array}{c}\text { Between } \\
\text { observer } \\
\text { and } \\
\text { observed - } \\
\text { shared } \\
\text { within } \\
\text { learning } \\
\text { set }\end{array}$ & $\begin{array}{c}\text { Between partner } \\
\text { colleagues }\end{array}$ \\
\hline
\end{tabular}

The peer development process outlined above was presented to all academic staff in the department as a voluntary alternative to the required peer observation of teaching. Those taking part were asked to submit a short proposal for their peer development project, followed up later by a short summary of outcomes and professional development wishes. All detail remained confidential between partners. The removal of the evaluative 'report' element was intended to maintain an emphasis on the developmental purpose of the process, rather than a judgement on the quality of their work.

\section{Results and discussion}

\section{Phase 1}

\section{Staff views regarding peer observation of teaching}

Analysis showed that some, if not all, of the problems associated in the literature with conventional peer observation of teaching were identified within the existing system by different members of staff. The themes that emerged focused on its perceived lack of value to the individual; the opacity of its relationship with performance management; and its inflexibility. 
The existing process was recognised as something to be done, a 'ticking the box' procedure to be accomplished each year for institutional purposes. According to Susie:

$\ldots$ it gives the final impression that management just want the boxes ticked to say that everyone has been observed. It's a tick-box culture.

Observations were considered not truly representative of the range of teaching activities in which staff were engaged, and outcomes did not have any major influence on individuals' teaching. Consequently, little or no change was made to teaching practice, resulting in minimal impact. Adam stated:

...these things can be said, noted down, but actually does anything happen with that? Not in my experience.

Whilst peer observation procedures were not directly or overtly used to grade teaching performance, there was a perception that poor peer observation records would not be helpful when it came to appraisal. Helen explained:

I worry that poor peer observation feedback will influence my yearly appraisal - I'm never sure how separate these two procedures are. I know they are meant to be separate but I'm just not convinced. Peer observation always feels like appraisal and nothing like mentoring.

Another theme was the inflexibility of the current peer observation scheme, restricted to the traditional large-group lecture in the main:

It needs to accommodate all modes of teaching e.g. supervision etc. (Jayne)

... and provide genuine opportunities for mentoring and development. (Ben)

Staff appeared to support the idea of a new scheme being introduced that could accommodate other forms of teaching activity, and which felt supportive to staff rather than judgemental. For example, Jess observed:

I like the idea of there being variable ways of fulfilling the accountability obligation so I would be suspicious of any one 'new scheme' that replaced the old one with an inflexible set of requirements.

Recognition of the issues associated with the existing peer observation system led to the design of the new, voluntary 'peer development' process.

\section{Phase 2: evaluation of the peer development process}

\section{Summary of projects}

26 academic teaching staff (37\% of the total academic workforce) were involved in ten different peer development activities during 2008-09. All levels of teaching staff, representing eight separate programmes, were included. Groups of two or more were formed, the largest involving five tutors teaching the same subject on the same programme. The projects provide a wide range of learning and teaching contexts including:

- Supervision of research students;

- Incorporating research into learning and teaching;

- Integrating ICT effectively into subject teaching;

- Planning and developing a new course;

- Effective use of tutorial support;

- The pedagogy of using the interactive whiteboard.

All groups engaged in meetings, sometimes supported by email correspondence. Interestingly, given that there was no requirement to do so, eight out of the ten groups chose to observe each other in action, in two cases combining this with episodes of shared teaching; this was followed up by discussion or 'feedback'. Three participants attended formal training sessions in the focus area, and disseminated to their peers. In some cases, a systematic and ongoing schedule of peer development events was clearly planned and organised. In others, it was more informal, slotted in at appropriate points during the year, and in at least one situation was focused on a particular point in the teaching calendar. 


\section{Initial motivations for engaging in peer development}

The questionnaire asked why participants had initially chosen to take part in the pilot peer development process. Figure 1 shows the range of explicit and often overlapping reasons provided. Over half were attracted by the opportunity to work with colleagues, and to plan a project which would impact directly on their own professional practice. Several were keen to pursue a particular existing interest, such as the role of the interactive whiteboard in mathematics teaching, or procedures for effective tutorials. Additionally, the opportunity to focus on activities not regarded as 'teaching' in the traditional sense, such as course planning or supporting students with written work, proved attractive, while one lecturer referred to her existing staff development role as a reason for participating.

\section{Figure 1: Motivations for engaging in peer development (17 responses)}

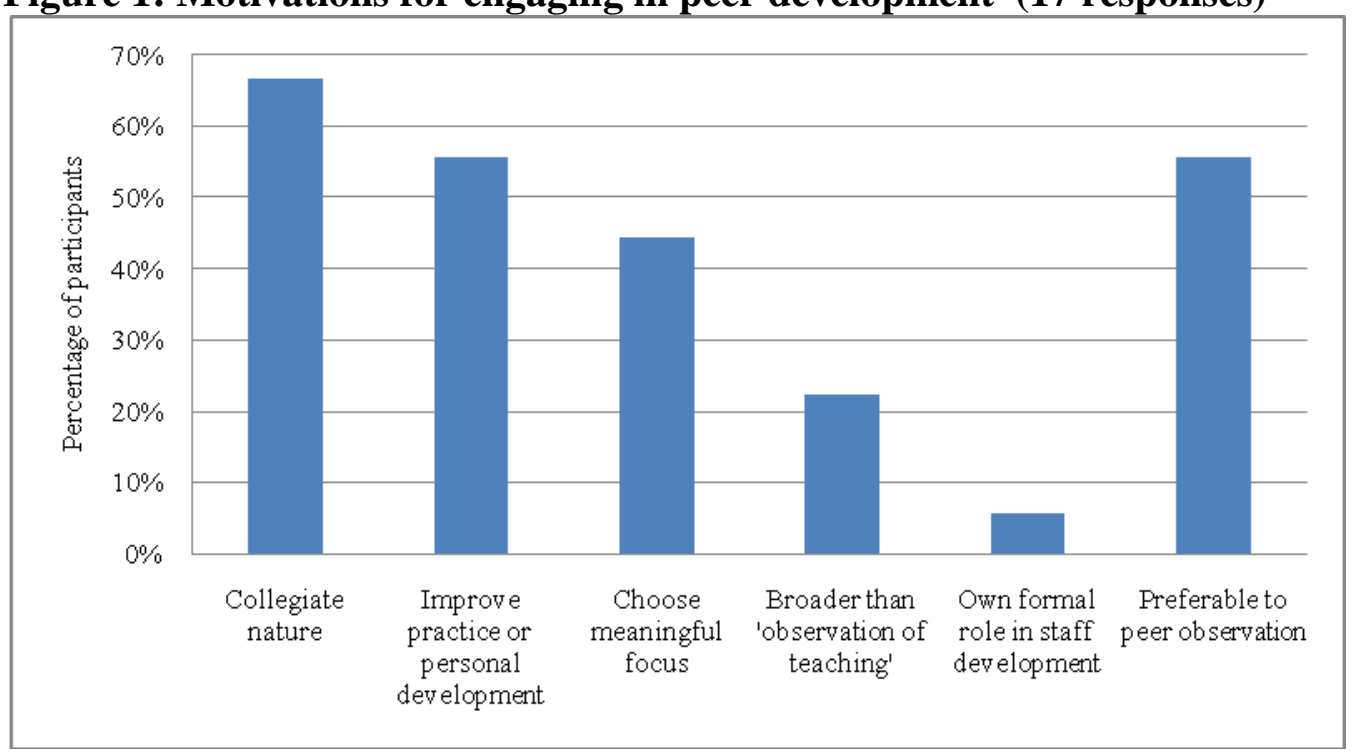

Reinforcing phase 1 findings, many respondents expressed the opinion that peer development had appeared to offer a more valuable alternative to peer observation. This overlapped with other overarching themes, notably a perception of increased collegiality; the feeling of engagement in authentic and worthwhile activity; the sense of autonomy offered by peer development; the view that genuine professional development was taking place. According to Anna:

It seemed less judgemental. A friendly, cooperative approach, an opportunity to get support with something I felt was meaningful and important to me - as opposed to doing something for the sake of it.

The interviews, while supporting these findings, included other reasons that strongly reflect dissatisfaction with the previous system. For example Joe's experience was that peer observations were overly introspective and that mutual back-slapping within a group of friends did not offer worthwhile feedback with potential to improve practice, whilst Paula felt that the concentration on face-to-face teaching limited professional development. Both welcomed peer development as a more rigorous process, and expressed a real desire to improve professionally in a meaningful manner. Joe explained:

I think the previous system was quite superficial, and fairly easy to get around, because I'd go and watch a colleague, someone I was friendly with, and the debriefing from that session would be usually pretty friendly, and then somebody else who was friendly with me would come in and watch my sessions, and in the course of two or three years we'd go around the loop... I thought this was a means of being a little bit more critical and perhaps learn a bit more through the system. 


\section{Views after engaging in the peer development process}

\section{Comparison of peer development with peer observation}

Participants continued to compare their experience of peer development favourably against that of peer observation after their first engagement with the new system. The questionnaire asked respondents to note explicitly the advantages and disadvantages of peer development compared to peer observation. The vast majority (89\%) viewed peer development as positively advantageous. Figure 2 shows the relative advantages of peer development, which, unsurprisingly, mirror its initial attractions (Figure 1).

Figure 2: Reasons for preferring peer development to peer observation (16 responses)

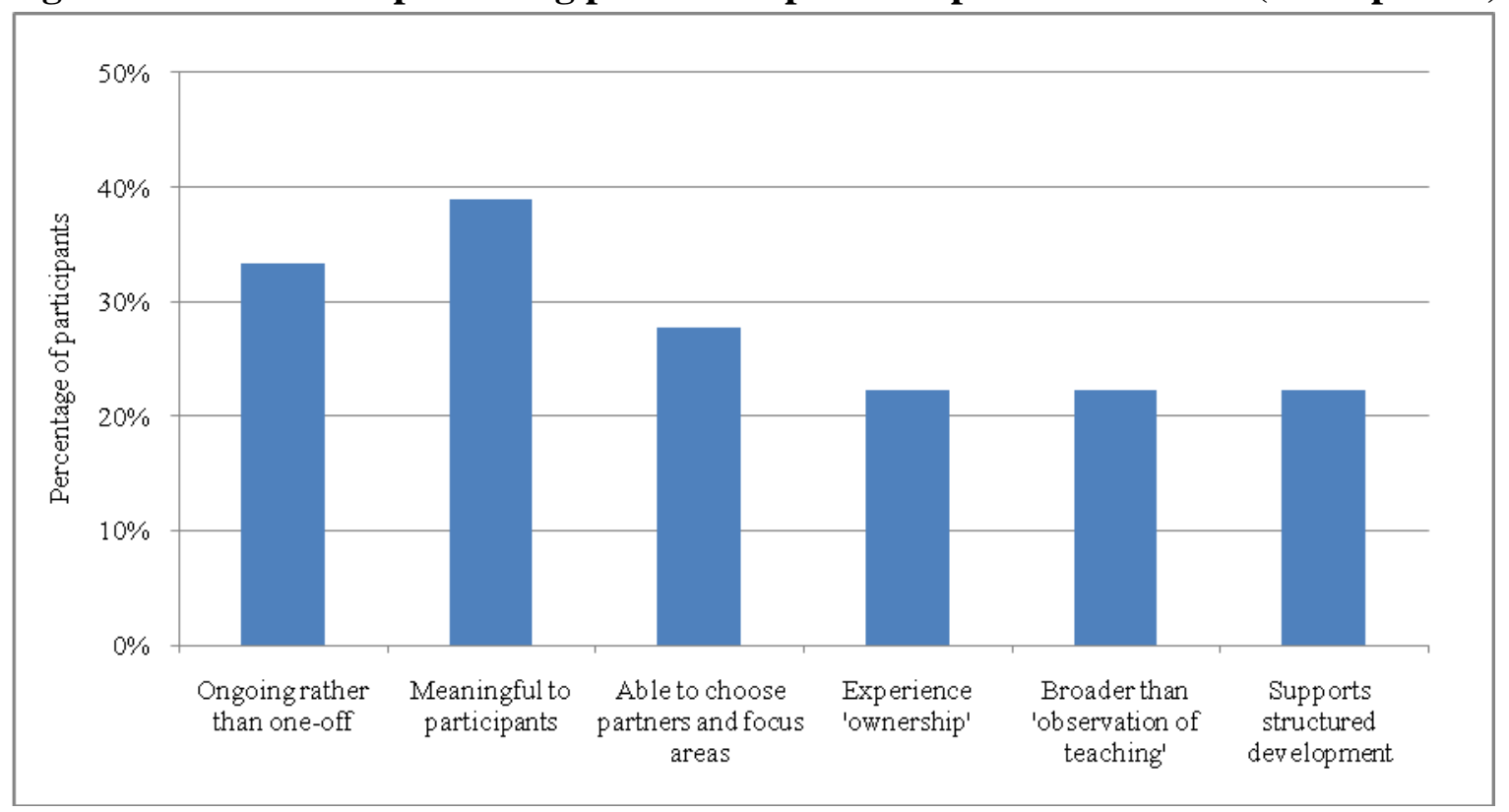

Participants found their chosen focus areas meaningful and of practical benefit to them; valued the longer-term process, often recognising that for maximum benefits the process needed to extend beyond one year; liked being able to work with partners who shared a common interest; felt in control of and responsible for their own development work; and valued the range of teaching-related activities they could focus on. Karen, for example, noted the more positive ethos:

Ethos of support rather than judgement. A better feel-good factor.

Meanwhile, Rose valued the sense of autonomy and collegiate experience over time: Opportunity to decide on the focus and therefore have a greater ownership of the process, working productively with another rather than having a 'one off' experience that isn't followed up.

Similar views were offered at greater length by interviewees, such as Joe:

It was partly because I felt that that peer observations were particularly unhelpful actually, and the peer observations that I've had in the three previous years of doing this haven't really highlighted anything that was groundbreaking or earth-shattering or really useful for any sort of professional development at all, really, so I wanted to do something that was going to have an impact on my professional development and on my working patterns.

\section{Positive outcomes}

Three questionnaire items explored how taking part in peer development had enhanced practice, or benefited self or peers. Figure 3 provides a summary of responses. These were 
wide-ranging, overlapping and, as might be expected, tended to coalesce within groups. Although most perceived benefits relate to selves, as individuals and groups, others relate to colleagues more widely and students.

\section{Figure 3: Benefits resulting from peer development (18 responses)}

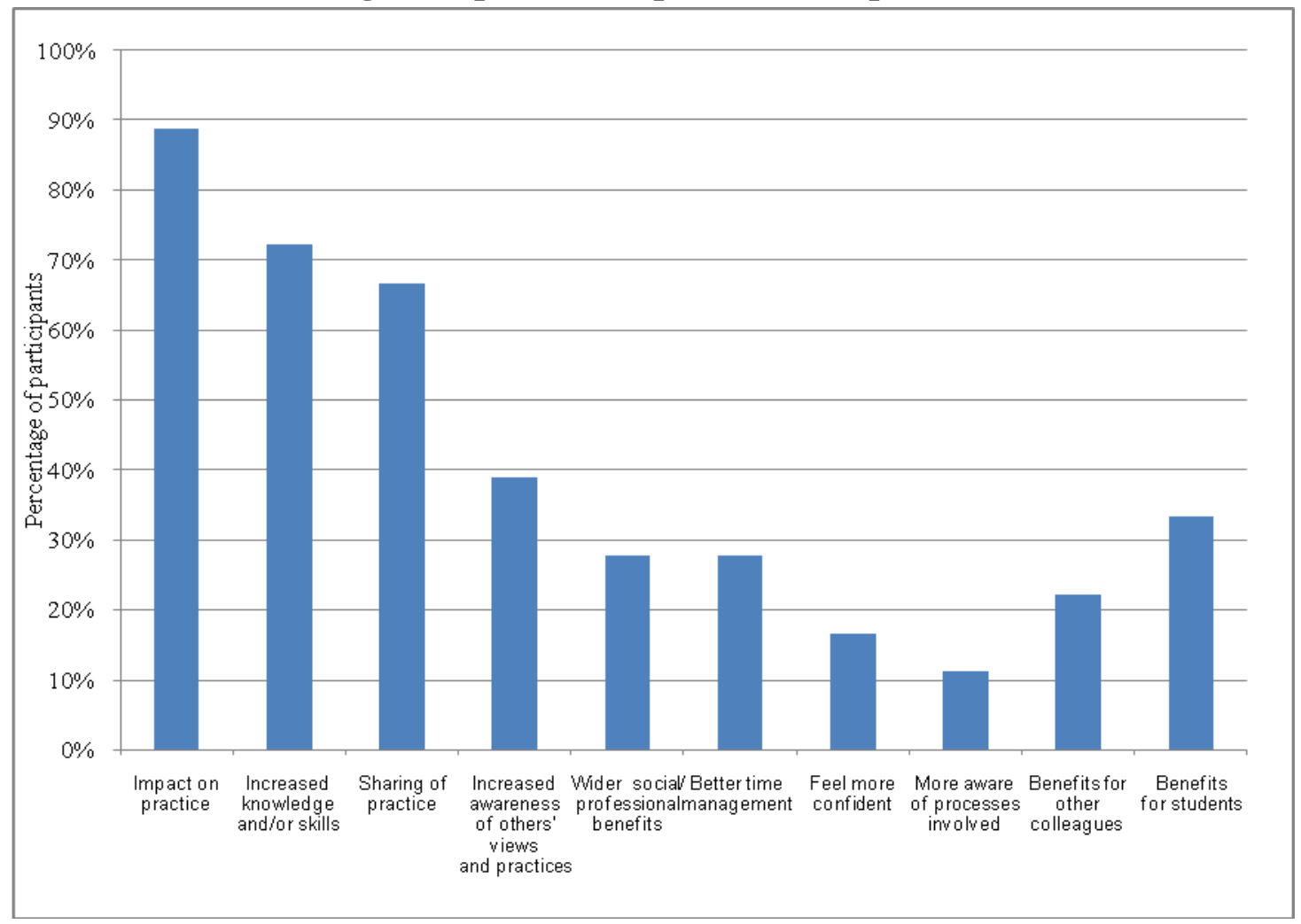

Participants felt overwhelmingly that peer development had real practical value and either had already impacted positively on their practice, or would do so in the future:

My use of IWB has improved... increased skills impacting on teaching for all of us; demonstrating better, i.e. more creative and interactive, use of an IWB to trainees. (Lianne)

I feel much more confident that I am dealing with individuals in tutorials appropriately and helpfully... I am better prepared to support students who have problems- particularly when these are mental health issues. This had been a concern in the past. (Sarah)

Others were of the view that peer observation had provided them with a mechanism to develop through engaging in professional dialogue with others in the group, as Roy explains:

...it sounds silly but it's the only time that I've actually had critical feedback to allow me to think this is something I need to go away and work on, usually it's 'that was fantastic', and so I go away feeling good, but that's no use... the discussions afterwards were very helpful in throwing around ideas, and finding out if we had a shared understanding or not, so that really from a personal point of view, that was good, what I was looking for, and hopefully feeding through to my teaching more effectively.

The collegiate nature of the process was further evidenced by the fact that it was often difficult to differentiate between benefits to respondents as individuals or to their groups. Paula, for example, states:

I think we shared a lot of practice, a lot of good practice, such as the way that we develop trainees and the way that we move them forwards was quite different actually between the three of us. So we shared that between us, and I think that we've all ended up taking some things away from other people and using them, it's quite difficult to define. 
Seven responses reported increased knowledge or skills, while almost as many asserted that sharing of practice in its own right was an important benefit. This was often related to becoming more aware of peers' understandings and practices:

I should think you just get that extra perspective, yes so, it worked, that third person just feeding in a different set of ideas progressed the discussion a little bit further, really. (Joe)

I still think we might have slightly different understandings of it and actually we still need to have some time to go through that. (Roy)

Five mentioned a range of wider social/professional benefits such as developing friendships, support systems and a greater sense of being part of a learning community. Five considered that aspects of their time management, as individuals or as a team, had improved; three felt more confident in the focus area; while two had increased their understanding of the processes involved in particular aspects of higher education.

Benefits for colleagues were also mentioned:

This should feed into how I support inexperienced $\mathrm{PhD}$ supervisors in their role. (Deborah)

We have produced information on student support that we have shared with all tutors. (Pam)

A third of participants referred to direct or indirect benefits for students, a point which was more strongly emphasised in the interview data. Sergei observed:

I think for the students... seeing that we are singing off the same hymn sheet is quite important. And I am hoping also that the session that I am doing in December will sort of make that clear.

\section{Negative outcomes}

The only disadvantage cited (5 responses, $28 \%$ ) was that peer development as a reflective process rather than a one-off annual event necessarily demanded more time than peer observation. Some groups, such as Roy's, recognised this as an issue which had limited the scope of their work:

...have you actually physically got the time to go and watch someone for $2 / 3$ hours? But we managed to do that, I found it interesting, I think we probably needed more time outside, just to sit down and talk and reflect.

The majority, however, claimed that the benefits outweighed the problem of finding time:

Takes more time but benefit outweighs this. Allows ongoing discussion on issue to be followed up, more structured process - felt less disjointed, got much more from it. (Jan)

This was by far the most constructively critical process I have engaged in. It requires more time but the benefits mean this is something we were happy to do. (Joe)

\section{Concluding comments}

Peer development was introduced, in response to staff concerns, as an alternative to peer observation of teaching. Most respondents did not specifically refer to peer observation as a system imposed by management for assessment purposes, with the associated negative consequences (Darbyshire, 2007; Hendry and Dean, 2002; Shore, 2008); however it does appear to have been something to be ticked off the annual job list. Such an attitude suggests compliance with University requirements rather than engagement (Hammersley-Fletcher and Orsmond, 2005; Shortland, 2004), resulting in a loss of rigour and a sense of complacency (Gosling, 2002). As peer observation did not require or promote critical debate and discussion 
about teaching, it was regarded as lacking any meaningful function, as a form of professional development or even as an auditing tool.

Our research indicates the genuine desire of participants to engage in a process that was worthwhile for them professionally, and peer development appears to have accomplished that by providing the opportunity to plan and create a project of personal value to self and colleagues. By offering a more holistic view of 'teaching', participants were able to choose an aspect of their practice that they wanted to improve through a process of their own devising, and their responses show that the opportunity to exercise autonomy and choice were highly appreciated. As Luchoomun (2007) notes, empowering staff to collaborate and take ownership of their professional development has positive outcomes for those involved.

Additionally, the opportunity for debate where colleagues did not feel threatened or undermined, but were mutually engaged in professional dialogue aimed at improvement, has led to an increased sense of collegiality, a critical factor in the development of learning communities (Schuck et al., 2008). Peer development seems to have had some impact on the way in which colleagues engage with one another, and there are optimistic signs for the development of a professional learning community. The potential for rigorous, effective and frank exchanges about aspects of practice within such 'safe' contexts was regarded as a major benefit of engaging in the peer development, and may be considered a key mechanism for improvement (Hammersley-Fletcher and Orsmond, 2004; Hendry and Dean, 2002; Peel, 2005). Such exchanges were focused on individuals as learners discussing a joint enterprise within the group, and as such could be deemed learning conversations (Allard et al., 2007; Bell, 2001; Haigh, 2005). However, a key issue that emerged was the need for time to take these conversations further and enable deeper reflection and greater reflexivity to transform practice (Wilcox, 2009). A will and desire to take part in such conversations clearly exists, and has been an important factor in their success (Aubusson et al., 2007), but if time is not built into the process, goodwill and even the desire to improve professionally may evaporate, and the peer development process along with it.

Furthermore, time is essential if peer development is to be sustained. Successful learning communities require engagement with specific aspects of practice over a period of time to enable particular issues to be teased out, discussed and reflected upon (FeimanNemser, 2001). Such longer-term commitment may be unsustainable unless staff are positively enabled to work together in this way, despite individuals' assertions that the benefits outweigh the costs. Managing time is indeed part of the responsibility of the professional learner, but if peer development is to become accepted as the norm, the institution will need to consider ways of legitimising the additional time required for this process.

Despite the enthusiasm for peer development displayed by those taking part, its uptake has been restricted to a minority of colleagues, who are largely based in specific programmes. This may lead, for example, to groups becoming overly introspective and self-satisfied, or sharing and accepting habitual practice without critical reflection. To avoid such 'pooled ignorance' groups should be encouraged to be fluid and flexible, routinely changing composition, so that fresh ideas and alternative practices are dialogically explored. In addition, few current participants hold promoted positions, and if a more inclusive learning community is to develop, a more representative involvement of staff across all levels and programmes is essential. The optimal way forward may be through an organic extension of peer development over time, as groups fluctuate and change focus, to encompass more staff members gradually, so that in time peer development becomes the system of choice.

In addition, disseminating areas of common interest which transcend specific courses and positions in the staff hierarchy may prove helpful in facilitating wider engagement. However, given the importance of personal autonomy within the process, it would be counterproductive to produce extensive structures or guidance, or impose a requirement of 
participation (Gosling 2002). There is an obvious tension between the ideals of autonomy and self-management embedded in the peer development process and the pressures on institutions to develop and manage systems in order to demonstrate their accountability. On the one hand, the peer development process is a liberating and individualistic process; on the other, institutional systems tend to become authoritarian, inflexible and bureaucratic impositions.

Nevertheless if peer development is to expand and become embedded in institutional practice, positive action needs to be taken to support its continuing development. This is likely to require its active promotion by management and some monitoring of its uptake and value in ways which evaluate the system, rather than participants. This may appear to be an extra layer of formality, but it is likely that without it the initiative may founder after a promising start. More powerful, however, would be an approach that shares experiences of professional learning within the wider community. Occasional workshops or seminars might provide a forum for groups to disseminate to and engage in constructive dialogue with others, and might also offer one route by which colleagues less known to each other can identify common interests which may lead to future collaboration. However if peer development is to be regarded by academic staff as a worthwhile enterprise it is essential that it remains owned and driven by committed and enthusiastic individuals and groups. This should ensure that it will flourish and promote effective and worthwhile 'learning communities' which can overcome the ever-present obstacle of lack of time.

Our findings suggest that many of the intended benefits of peer development have been realised, for individuals and small groups that we consider will have resonance for colleagues in institutions elsewhere in the UK and beyond. These benefits have been achieved in the short term, and if the impact of peer development is to become longer-term and selfsustaining the initiative needs to become embedded in institutional ways of working to the point that it becomes the norm, so that as many colleagues as possible can benefit from the experience. As Anna points out:

Opportunity to get support with something I felt was meaningful and important to me - as opposed to doing something for the sake of it... more choice, more control, more meaningful - please keep this going, it's great!

\section{References}

Allard, C.C., Goldblatt, P. F., Kemball, J.I.,Kendrick, S. A., Millen, K. J. Smith, D. M. (2007). Becoming a reflective community of practice. Reflective Practice, 8, 3: 299-314.

Aubusson, P., Steele, F., Dinham, S. and Brady, L. (2007). Action learning in teacher learning community formation: informative or transformative? Teacher Development, 11, 2: 133-148.

Babbie, E. (2009). The Practice of Social Research, 12 $2^{\text {th }}$ Edition. Belmont, CA: Wadsworth Cengage Learning.

Bell, M. (2001). Supported reflective practice: a programme of peer observation and feedback for academic teaching development. The International Journal for Academic Development, 6, 1: 29-39.

Bennett, S. and Barp, D. (2008). Peer observation - a case for doing it online. Teaching in Higher Education, 13, 5: 559-570.

Berthiaume, D. (2006). Peer observation of teaching in higher education. Learning and Teaching Enhancement Unit, University of Southampton.

Carr, W. and Kemmis, S. (1986). Becoming Critical. Education, knowledge and action research, Lewes: Falmer.

Darbyshire, P. (2007). Never mind the quality, feel the width: the nonsense of quality, excellence and audit in education, health and research. Collegian, 15: 35-41.

Feiman-Nemser, S. (2001). From preparation to practice: Designing a continuum to strengthen and sustain teaching. Teachers College Record 103: 1013-55.

Foucault, M. (1979). Discipline and punishment. London: Allen Lane. 
Gosling, D. (2002). Models of peer observation of teaching. LTSN Generic Centre.

Gosling, D., and O'Connor, K. (2006). From peer observation of teaching to Review of Professional Practice (RPP): A model for continuing professional development. Educational Developments, 7, 3: 1-4.

Haigh, N. (2005). Everyday conversation as a context for professional learning and development. International Journal for Academic Development, 10,1:3-16.

Hammersley-Fletcher, L. and Orsmond, P. (2004). Evaluating our peers: is peer observation a meaningful process? Studies in Higher Education, 29, 4: 489-503.

Hammersley-Fletcher, L. and Orsmond, P. (2005). Reflecting on reflective practices within peer observation. Studies in Higher Education, 30, 2: 213-224

Hendry, G.D. and Dean, S.J. (2002). Accountability, evaluation of teaching and expertise in higher education. The International Journal for Academic Development, 7, 1: 75 -82.

Kell, C. (2005). Embedding peer review of teaching into departmental practice. Paper presented at the British Educational Research Association annual conference, University of Glamorgan. http://www.leeds.ac.uk/educol/documents/144000.htm (accessed May, 2009).

Le Cornu, R. (2005). Peer mentoring: engaging pre-service teachers in mentoring one another. Mentoring and Tutoring, 13, 3: 355-366.

Little, P.F.B. (2005). Peer coaching as a support to collaborative teaching. Mentoring and Tutoring, 13, 1: 83-94.

Luchoomun, D. (2007). The Resilience of the "Corporate" in Post-Corporate Teacher Appraisal: A case study from Mauritius'. Asia Pacific Journal of Education, 27, 2: 189-205.

Marshall, B. (2004). Learning from the academy: From peer observation of teaching to peer enhancement of learning and teaching. Journal of Adult Theological Education, 1, 2: 185204.

McMahon, T., Barrett, T, and O'Neill, G. (2007). Using observation of teaching to improve quality: Finding your way through the muddle of competing conceptions, confusion of practice and mutually exclusive intentions, Teaching in Higher Education 12, 4: 499-511.

Peel, D. (2005). Peer observation as a transformatory tool? Teaching in Higher Education 10, 4: 489-504.

Shore, C. (2008). Audit culture and Illiberal governance. Anthropological Theory; 8, 3: 278 -298.

Shortland, S. (2004). Peer observation: a tool for staff development or compliance? Journal of Further and Higher Education, 28, 2: 219-228.

Schuck, S., Aubusson, P. and Buchanan, J. (2008). Enhancing teacher education practice through professional learning conversations. European Journal of Teacher Education, 31, 2: 215227.

Strauss, A. and Corbin, J. (1998). Basics of Qualitative Research: techniques and procedures for developing grounded theory ( $2^{\text {nd }}$ edition) Thousand Oaks, California: Sage.

Wilcox, S. (2009). Transformative educational development scholarship: beginning with ourselves. International Journal for Academic Development, 14,2:123-132

Zwart, R.C., Wubbels, T. Bergen, T.C.M. and Bolhius, S. (2007). Experienced teacher learning within the context of reciprocal peer coaching. Teachers and Teaching; Theory and Practice, 13, 2: 165-187. 